\title{
36 BUILDING CAPACITY FOR E-GOVERNMENT: Contradictions and Synergies in the Dialectics of Action Research
}

\author{
David Wastell \\ University of Manchester \\ Peter Kawalek \\ University of Manchester \\ Mike Newman \\ University of Manchester \\ Mike Willetts \\ Salford City Council

\section{Peter Langmead-Jones} \\ Lancashire Constabulary
}

Action research has been widely espoused within IS as a methodology for achieving relevant research, simultaneously addressing problems pertinent to practice as well as generating valuable IS theory. Debate, however, continues to revolve around the standing of action research. The need to address an applied problem as well as the imperative to deliver substantive research findings builds a degree of conflict into the process of action research (McKay and Marshall 2001) which has led some commentators to doubt whether action research is viable. In contrast, we believe that action research is not only feasible but an essential tool for developing and evaluating social theory. However, the need to serve the two masters of practice and research, at the heart of the action research dialectic, inevitably constrains the research process. The exigencies of practical problem solving and the need to deliver solutions limit the time and resources available for rigorous data collection and validation, and constrain the research agenda. Nonetheless the theory generated by action research reflects the dynamics and complexity of the real world milieu in which it was developed. Rather 
than a weakness, we see this as source of strength. The theory is richer, more relevant and holistic than its conventional counterpart. Moreover, it has been evaluated in the crucible of real-world intervention.

In this panel we explore some of the inherent conflicts of action research, seeking to show how the interaction of the practice and research can act as fertile source of new academic theory and a test-bed for established concepts. Electronic government will be the main application domain addressed. This is an important area for collaborative research between academic institutions and the practitioner community. E-Government imperatives present public sector agencies with formidable challenges, and joint work with research organizations can help build the new capacities that will be required to successfully embrace the modernization agenda. Two projects will be highlighted. First, the CRM Academy. Here the aim is to establish a research center providing tools, methods and mentoring to support the implementation of CRM within the local government sector. Manchester Business School is the lead research organization; Salford City Council the main practitioner partner. The work is based on earlier action research project which developed a BPR toolkit for implementing e-Govemment (Wastell et al. 2001). The second project (MADE) was aimed at the design and implementation of a multiagency decision support environment to support partnership work in the area of community safety. The project involved collaboration with Lancashire Constabulary and Lancashire County Council. The facility was successfully implemented in 2001 (Wastell et al. 2004) and has been used by all Districts across Lancashire in their crime auditing and performance monitoring activities.

\section{REFERENCES}

McKay, J., and Marshall, P. "The Dual Imperatives of Action Research," Information Technology and People (14), 2001, pp. 46-59.

Wastell, D. G.; Kawalek, P.; Langmead-Jones, P.; and Ormerod, R. "Information Systems and Partnership in Multi-agency Networks: an Action Research Project in Crime Reduction," Information and Organisation, 2004 (in press).

Wastell, D. G.; Kawalek, P.; and Willetts, M. "Designing Alignment and Improvising Change: Experiences in the Public Sector Using the SPRINT Methodology," in S. Smithson, J. Gricar, M. Podlogar, and S. Avgerinou (Eds.) Proceedings of the $9^{\text {th }}$ European Conference on Information Systems, Bled, Slovenia, 2001. 